\title{
Hepatitis C Treatment Uptake by New Prescribers After the Introduction of Direct Acting Antivirals
}

Shashi N. Kapadia, MD, MS ${ }^{1,2}$, Phyllis Johnson, MBA ${ }^{2}$, Bruce R Schackman, PhD ${ }^{2}$, and

Yuhua Bao, PhD²

'Division of Infectious Diseases, Weill Cornell Medicine, New York, NY, USA; '² Department of Healthcare Policy and Research, Weill Cornell Medicine, New York, NY, USA.

J Gen Intern Med 35(3):975-7

DOI: $10.1007 / \mathrm{s} 11606-019-05200-6$

(C) Society of General Internal Medicine 2019

\section{INTRODUCTION}

Hepatitis $\mathrm{C}(\mathrm{HCV})$ treatment has undergone a revolution since the introduction of highly effective, all-oral, once-daily direct acting antiviral (DAA) regimens in 2014. The previous less effective and more toxic regimens, which included injectable interferon, required frequent clinical and laboratory monitoring. Access to interferon-based treatment was limited by specialist access. ${ }^{1,2}$ DAAs do not require intense monitoring, and non-specialist providers can offer this simpler treatment. ${ }^{3} \mathrm{We}$ analyzed the change in the number, specialty, geographic distribution, and average volume of commercially insured patients among HCV-treating providers in the USA after the introduction of DAAs.

\section{METHODS}

We used 2013-2015 data from the Health Care Cost Institute (HCCI) database, which contains claims from over 50 million commercially insured individuals from 3 large insurers across all 50 states, including Medicare Advantage and health insurance marketplace plans. ${ }^{4}$ Providers were included if they were the prescriber of $\geq 1$ prescription claim for any $\mathrm{HCV}$ antiviral medication (except ribavirin, which is also used for other indications). We compared providers who prescribed $\mathrm{HCV}$ medication in 2013 (before all-oral DAA regimens were introduced) to 2015 (after DAAs were introduced). We described changes in the number, specialty, and county location of providers, and the median volume of HCV-treated patients per provider. Gastroenterologists were labelled as "gastroenterology or hepatology," as these could not be distinguished in HCCI, and internal medicine and family medicine were combined as "IM/FM." We constructed Lorenz curves and calculated Gini coefficients for the volume of patients treated by each prescriber, to examine whether the concentration of $\mathrm{HCV}$-treated patients among providers changed after DAAs were introduced. ${ }^{5}$ Gini coefficients

Published online July 19, 2019 quantify the degree of concentration, and are measured on a $0-1$ scale, with 0 being perfectly evenly distributed. Analyses were conducted in $\mathrm{R}$ v3.3.1 (using the DescTools, usmap, and ggplot2 packages). ${ }^{6}$

\section{RESULTS}

The number of HCV-treating providers increased from 2106 (treating 3025 patients) in 2013 to 6863 (20,998 patients) in 2015. Gastroenterologists/hepatologists remained the most abundant specialty and treated the majority of patients in both years, but the largest percentage increase in number of providers was seen in IM/FM (Table 1). The number of counties with at least one HCV treatment provider increased from 540 (covering $71 \%$ of US population) to 853 ( $81 \%$ of US population).

Treatment became more concentrated among providers over time. This was the net result of a large increase in the number of patients treated by high-volume prescribers, which increased concentration, along with an influx of new prescribers, which decreased it. In 2013, the top $25 \%$ of providers prescribed treatment for $49 \%$ of patients (Gini coefficient

Table 1 Number of Providers Offering Treatment and Patients Treated in 2013 and 2015

\begin{tabular}{|c|c|c|c|c|c|c|}
\hline & \multicolumn{3}{|c|}{$\begin{array}{l}\text { Providers offering } \\
\text { treatment }\end{array}$} & \multicolumn{3}{|c|}{ Patients treated* } \\
\hline & $\begin{array}{l}\text { No. } \\
\text { in } \\
2013\end{array}$ & $\begin{array}{l}\text { No. } \\
\text { in } \\
2015\end{array}$ & $\begin{array}{l}\% \\
\text { change }\end{array}$ & $\begin{array}{l}\text { No. } \\
\text { in } \\
2013\end{array}$ & $\begin{array}{l}\text { No. in } \\
2015\end{array}$ & $\begin{array}{l}\% \\
\text { change }\end{array}$ \\
\hline $\begin{array}{l}\text { GI/ } \\
\text { hepatology }\end{array}$ & 1420 & 4347 & $206 \%$ & 2089 & 14,005 & $570 \%$ \\
\hline $\mathrm{IM}^{\mathrm{F}} \mathrm{FM}^{\ddagger}$ & 187 & 880 & $371 \%$ & 311 & 2257 & $626 \%$ \\
\hline $\begin{array}{l}\text { Infectious } \\
\text { diseases }\end{array}$ & 132 & 571 & $333 \%$ & 174 & 1425 & $719 \%$ \\
\hline $\begin{array}{l}\text { Non- } \\
\text { physician } \\
\text { providers }\end{array}$ & 207 & 670 & $224 \%$ & 348 & 2709 & $678 \%$ \\
\hline $\begin{array}{l}\text { Other or } \\
\text { unknown }\end{array}$ & 160 & 395 & $247 \%$ & 209 & 837 & $427 \%$ \\
\hline Total & 2106 & 6863 & $226 \%$ & 3131 & 21,233 & $578 \%$ \\
\hline
\end{tabular}

*Patients may be counted more than once as some had multiple prescribers

${ }^{+}$GI/hepatology: gastroenterology or hepatology providers

IM/FM: internal medicine or family medicine providers 


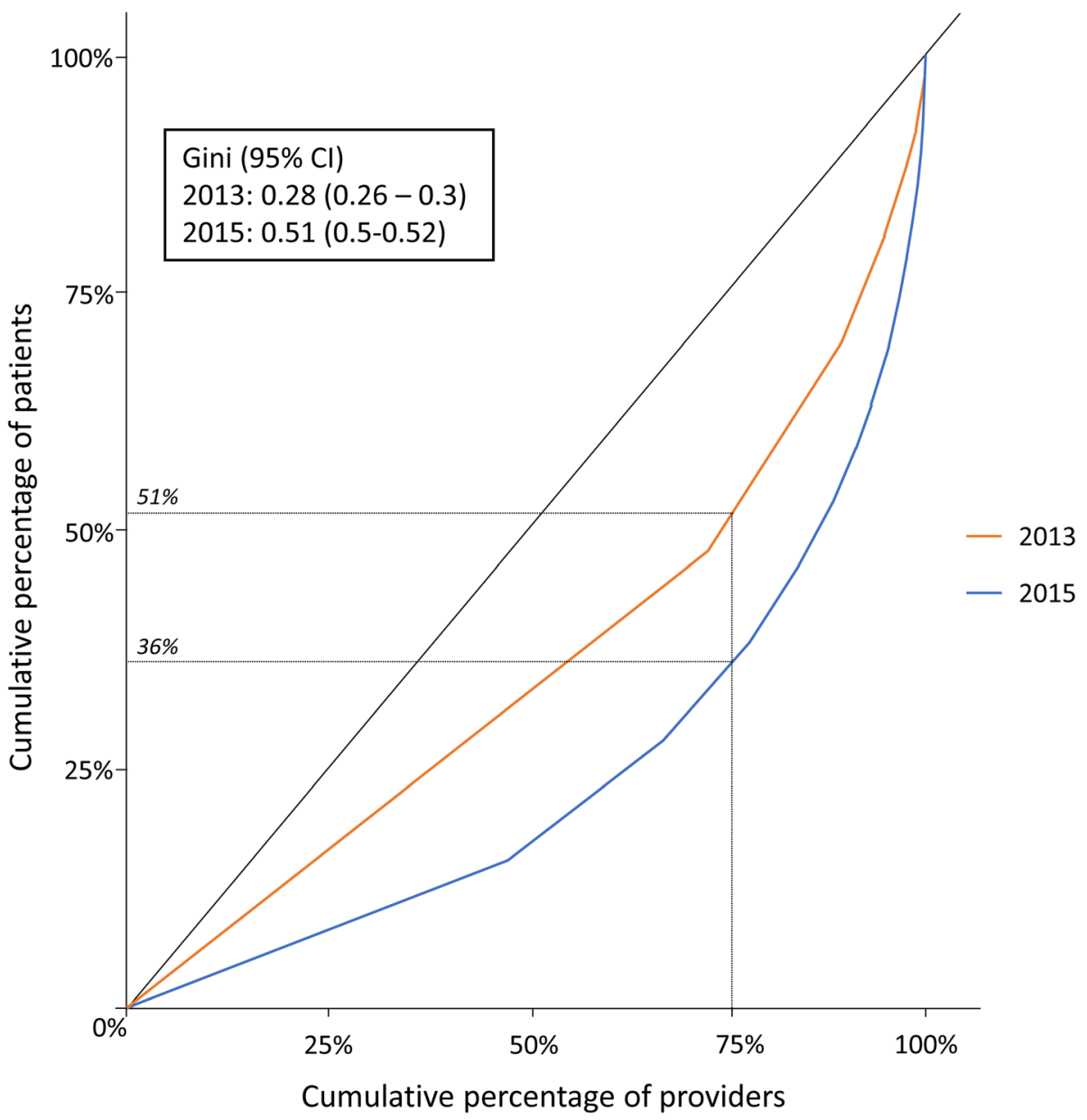

Figure 1 Concentration of HCV-treated patients among providers. Solid line represents line of perfect equality. Dashed lines show values for the 75th percentile of providers in each year. Gini coefficients represent the area between the Lorenz curve and the line of perfect equality, with 0 being perfectly equally distributed and 1 being perfectly unequal.

0.28). In 2015 , the top $25 \%$ of prescribers treated $64 \%$ of patients (Gini 0.56) (Fig. 1). For the 1450 providers that were prescribing medication in both years, the median volume of treated patients increased from 1 in 2013 (range, 1-19) to 3 in 2015 (range, 1-98). Additionally, 5413 new prescribers were present in 2015, with a median volume of 1 (range, 1-72).

\section{CONCLUSION}

Our findings show a rapid rise in the utilization of $\mathrm{HCV}$ treatment for commercially insured individuals, accompanied by increasing provider uptake of this revolutionary new treatment. Most patients continued to be treated by specialists. Prescribing became more concentrated among high-volume providers, who saw large increases in volume. However, the overall increase in number of providers, especially IM/FM, and new areas with treating providers, may signify improving access for patients who were previously unable to engage in treatment. These trends may evolve over time and may vary for other payers, such as Medicaid or Medicare, whose enrollees are more vulnerable and may be less engaged in care.
Corresponding Author: Shashi N. Kapadia, MD, MS; Department of Healthcare Policy and Research, Weill Cornell Medicine, New York, NY, USA (e-mail: shk9078@med.cornell.edu).

Funding Information This work was funded by the National Institute on Drug Abuse (P3O DA040500) and the National Institute of Mental Health (T32 MHO73553).

\section{Compliance with Ethical Standards:}

Conflict of Interest: Dr. Kapadia is a co-investigator on research grants paid to Weill Cornell Medicine from Gilead Sciences Inc., unrelated to this work. All other authors report no conflicts of interest.

\section{REFERENCES}

1. Westergaard RP, Stockman LJ, Hyland HA, Guilfoyle SM, Fangman JJ, Vergeront JM. Provider Workforce Assessment in a Rural Hepatitis C Epidemic: Implications for Scale-up of Antiviral Therapy. J Prim Care Community Health 2015;6(3):215-217.

2. Skeer MR, Ladin K, Wilkins LE, Landy DM, Stopka TJ. 'Hep C's like the common cold': understanding barriers along the HCV care continuum among young people who inject drugs. Drug Alcohol Depend 2018;190:246-254. 
3. Kapadia SN, Marks KM. Hepatitis C Management Simplification From Test to Cure: A Framework for Primary Care Providers. Clin Ther 2018;40(8):1234-1245.

4. HCCI: Healthcare Cost Institute. 2018; http://www.healthcostinstitute. org/access-data/accessing-hcci-data-2018/. Accessed January 25, 2018.

5. Guan Q, Khuu W, Spithoff S, et al. Patterns of physician prescribing for opioid maintenance treatment in Ontario, Canada in 2014. Drug Alcohol Depend 2017;177:315-321.
6. R: A language and environment for statistical computing [computer program]. Vienna, Austria: R Foundation for Statistical Computing; 2017.

Publisher's Note Springer Nature remains neutral with regard to jurisdictional claims in published maps and institutional affiliations. 